\title{
PNA/dsDNA Complexes: Site Specific Binding and dsDNA Biosensor Applications
}

Erin Shammel Baker, ${ }^{a}$ Janice W. Hong, ${ }^{a}$ Brent S. Gaylord, ${ }^{a, b}$ Guillermo C. Bazan ${ }^{a, b, *}$ and Michael T. Bowers $^{a, *}$

Department of Chemistry \& Biochemistry, ${ }^{\mathrm{a}}$ Department of Materials, ${ }^{\mathrm{b}}$ Center for Polymers and Organic Solids, University of California, Santa Barbara, CA 93106

bazan@chem.ucsb.edu, bowers@chem.ucsb.edu

\section{Supporting Information}

\section{Full Reference}

39. Case, D. A.; Pearlman, D. A.; Caldwell, J. W.; Cheatham III, T. E.; Wang, J.; Ross, W. S.; Simmerling, C. L.; Darden, T. A.; Merz, K. M.; Stanton, R. V.; Cheng, A. L.; Vincent, J. J.; Crowley, M.; Tsui, V.; Gohlke, H.; Radmer, R. J.; Duan, Y.; Pitera, J.; Massova, I.; Seibel, G. L.; Singh, U. C.; Weiner, P. K.; Kollman, P. A. AMBER 7; University of California: San Francisco, 2002. 


\section{Additional FRET Experiments}

P-Fl to $C_{A} / C_{B}$ ratios of 2.5:1, 7.5:1 and 15:1 were examined. The P-Fl to $C_{A} / C_{B} 2.5: 1$ ratio is shown in orange, the 7.5:1 ratio is blue, and the 15:1 ratio is red. Increased emission was observed with increasing P-Fl concentration. The P-Fl to $\mathrm{N}_{\mathrm{A}} / \mathrm{N}_{\mathrm{B}} 15: 1$ ratio is shown in black.

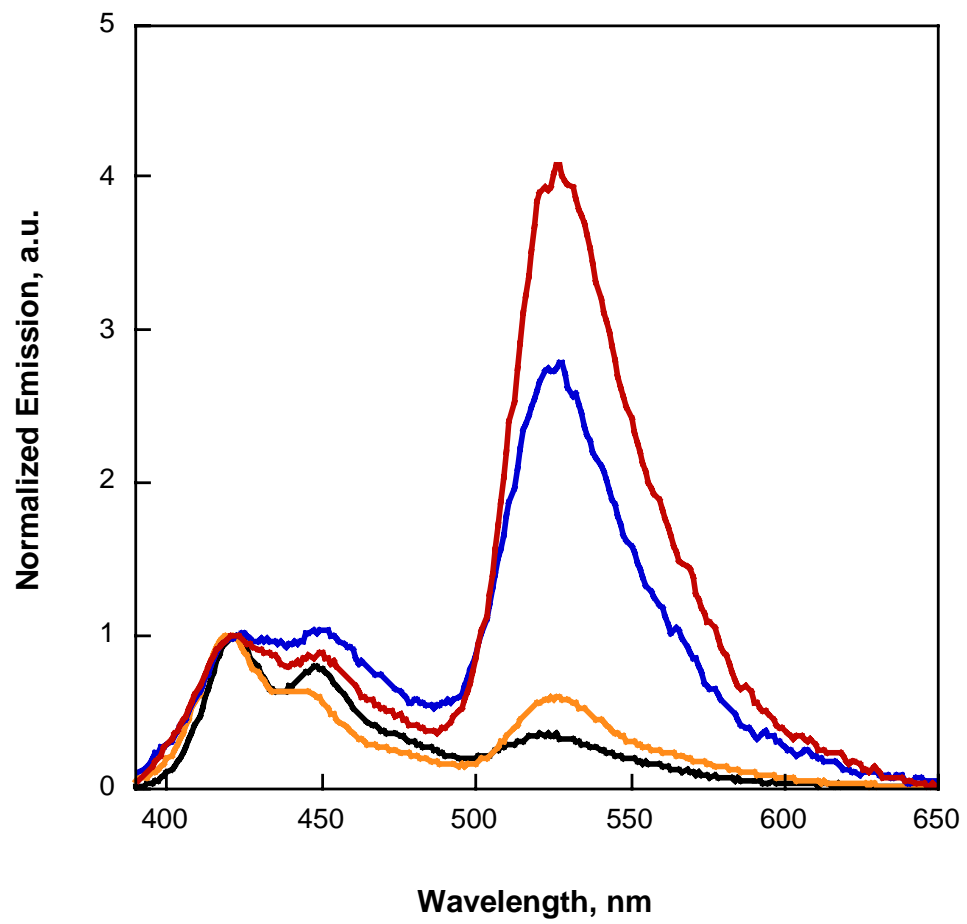




\section{Additional Mass Spectra}

P-Fl to $C_{A} / C_{B}$ ratios of 2.5:1, 7.5:1 and 15:1 were examined with mass spectrometry to determine how different concentrations of $\mathrm{P}$ effect complexation. The three different ratios are illustrated below.

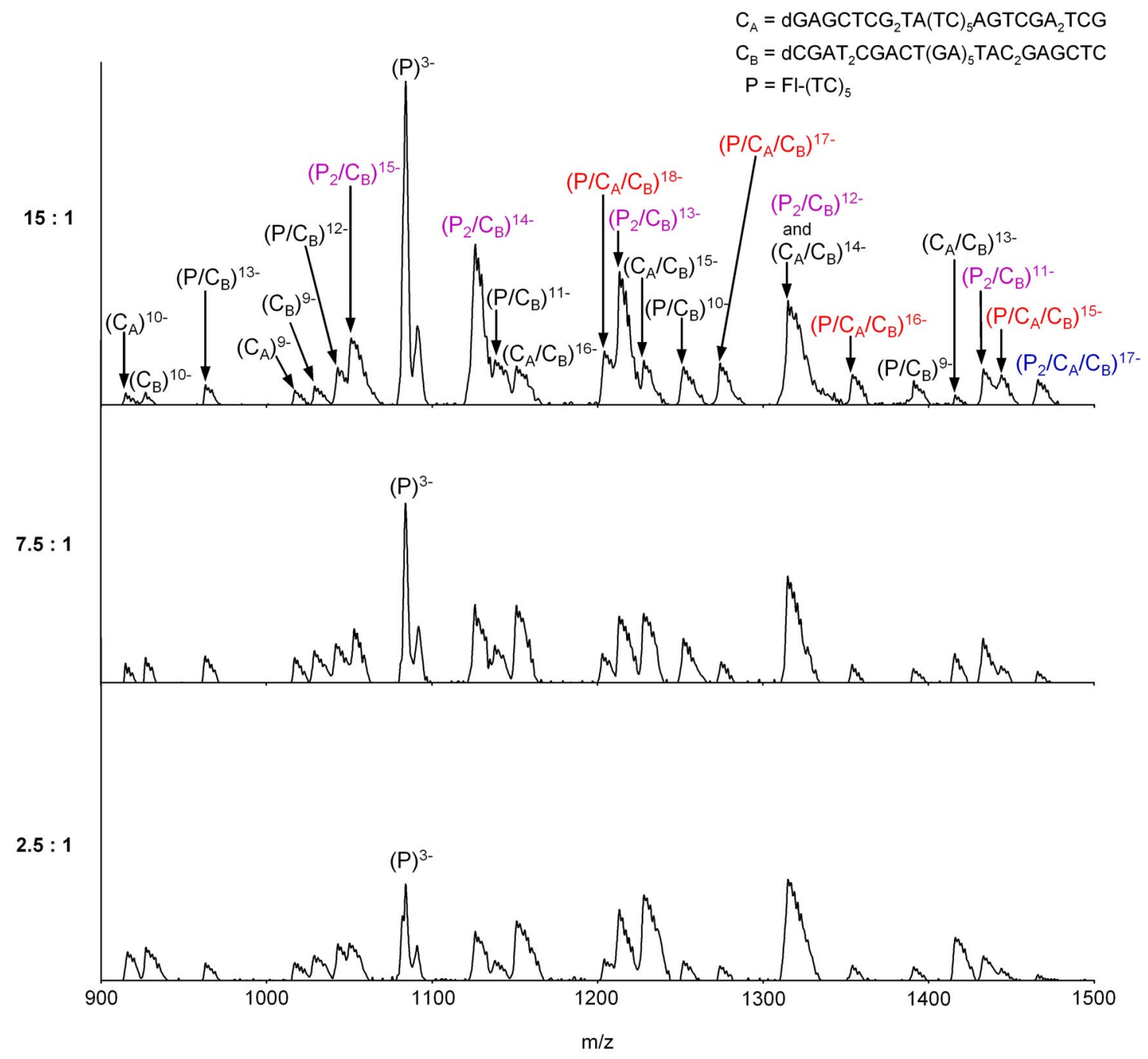

